\title{
Bleeding Post Constriction Ring Release Surgery Causing Lower Limb Ischemia in an Infant with Undetected Hemophilia B
}

\author{
S. Raja Sabapathy ${ }^{1}$ Monusha Mohan ${ }^{1}$ \\ 1Department of Plastic, Hand and Reconstructive Microsurgery, \\ Ganga Hospital, Coimbatore, Tamil Nadu, India \\ 2Department of Anaesthesiology, Ganga Hospital, Coimbatore, \\ Tamil Nadu, India \\ ${ }^{3}$ Visiting Pediatric hematologist, Ganga Hospital, Coimbatore, Tamil \\ Nadu, India \\ Indian J Plast Surg 2021;54:218-220.
}

G. Venkateswaran ${ }^{2}$ Shashi Ranjani

\author{
Address for correspondence $S$. Raja Sabapathy, MS, MCh, \\ DNB, FRCS, FAMS, DSc, Division of Plastic Surgery, Hand and \\ Reconstructive Microsurgery, Ganga Hospital, 313, Mettupalayam \\ Road, Coimbatore, Tamil Nadu 641043, India \\ (e-mail: rajahand@gmail.com).
}

\begin{abstract}
Keywords

- hemophilia

- constriction ring syndrome

- postoperative bleeding

Bleeding in the immediate postoperative period causing compromised limb circulation is an alarming complication. It is known to occur in coagulation disorders like hemophilia. When such complications happen in a child with no previous history of bleeding problems, one has to have a low threshold for suspecting a coagulation disorder. Repeated diffuse bleeding in the whole of the surgical wound with no specific bleeders must raise the suspicion and appropriate laboratory tests must immediately be ordered. Bleeding in coagulation disorders can stop only with supplementation of the appropriate missing clotting factor. Early diagnosis is important to avoid excess morbidity. We are reporting a 6-month-old child who underwent surgery for constriction ring syndrome in the limbs with Z-plasty and developed impending limb ischemia due to bleeding in the immediate postoperative period. The article emphasizes the need to think of the possibility while encountering recurrent bleeding in the postoperative period.
\end{abstract}

\section{Introduction}

Bleeding in the immediate postoperative period causing impending limb ischemia is a worrisome complication when it happens following surgery to correct congenital differences in a child. Hemophiliacs are uniquely at risk for these complications. Possibility of hemophilia must be entertained when unusual bleeding episodes occur in children post surgery. We report the case of a 6-month-old baby who developed impending limb ischemia due to postoperative bleeding following Z-plasty for constriction ring release in the leg.

\section{Case Report}

A 6-month-old male child, second born to parents of second-degree consanguineous marriage was brought with

published online

June 10, 2021
DOI https://doi.org/

10.1055/s-0041-1729509 ISSN 0970-0358 constriction rings affecting all four limbs. Two constriction bands were noted in the right leg, one below the knee and another above the ankle with significant distal swelling (-Fig. 1). A circumferential constriction ring was present in the right thumb at the interphalangeal joint crease, with distal edema. The baby had amputation of the right index, middle, and ring fingers at the proximal interphalangeal joint level. The short fingers had syndactyly.

Constriction ring release and Z-plasty was performed in the right thumb and leg (-Fig. 2), releasing $70 \%$ of the circumference. Syndactyly separation of the right third web was done, and raw areas were covered with full thickness skin graft from the left groin.

Six hours post surgery, the lower limb dressings were soaked with blood. On examination in the operation theater, there was diffuse ooze from the skin flap edges with

\footnotetext{
(C) 2021. Association of Plastic Surgeons of India.

This is an open access article published by Thieme under the terms of the Creative Commons Attribution-NonDerivative-NonCommercial-License, permitting copying and reproduction so long as the original work is given appropriate credit. Contents may not be used for commercial purposes, or adapted, remixed, transformed or built upon. (https://creativecommons.org/licenses/by-nc-nd/4.0/).

Thieme Medical and Scientific Publishers Pvt. Ltd. A-12, 2nd Floor, Sector 2, Noida-201301 UP, India
} 


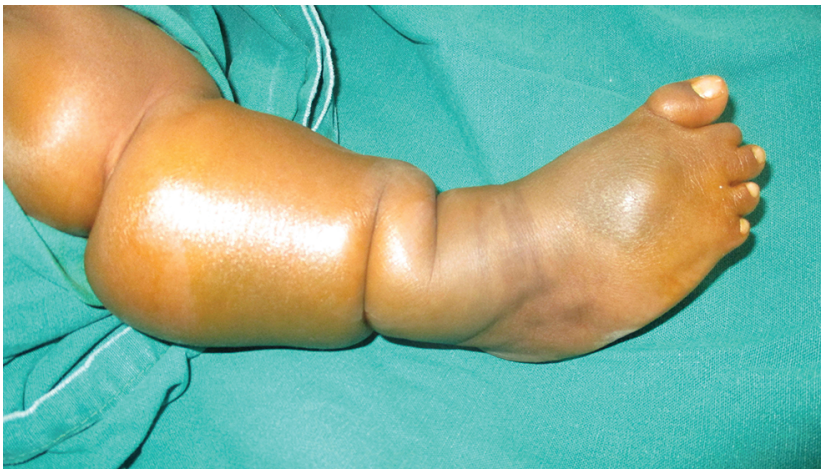

Fig. 1 Preoperative picture showing the constriction rings around the leg with distal swelling.

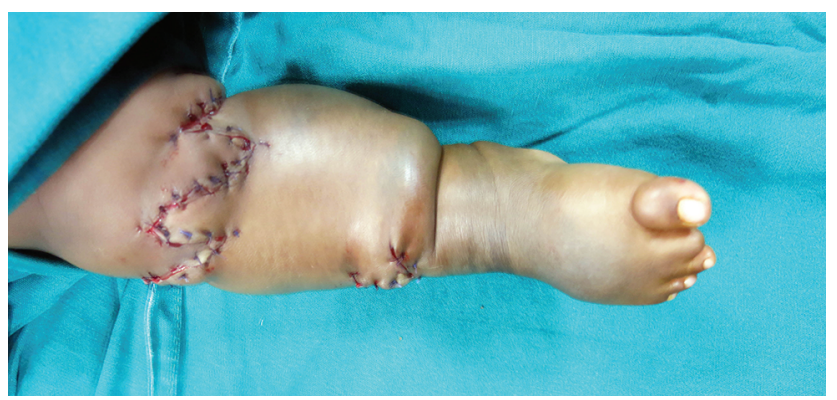

Fig. 2 Immediate postoperative period after releasing the constriction rings with Z-plasty.

no specific active bleeders. We reinforced the skin sutures. The hand and groin wounds were given compression dressings. Eight hours later the leg dressings were heavily soaked. Diffuse bleeding was present on re-exploration. We administered $20 \mathrm{~mL}$ fresh frozen plasma (FFP) and $130 \mathrm{~mL}$ packed red blood concentrates (PRBC). Six hours later, the next day morning, the baby was comfortable.

By midday, the child was found crying incessantly. The bandage was tight around the proximal leg. The dressings were removed. A fresh bout of bleeding had occurred, with hematoma spreading in the subcutaneous tissue planes. The limb was dark, the skin cold to touch and the capillary refill

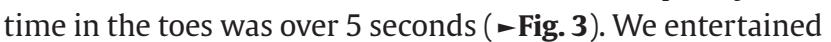
the possibility of a coagulation disorder. On further history taking, the mother said that she had severe bleeding during previous childbirth and grandmother too had bleeding episodes after trivial trauma.

The hemoglobin level was $4.5 \mathrm{~g} / \mathrm{dL}$ and the Activated partial thromboplastin time was 70.6 seconds (normal: 25-35 seconds). Prothrombin time was normal. We administered $100 \mathrm{~mL}$ PRBC and $80 \mathrm{~mL}$ FFP. The leg became warmer, but skin blisters erupted on the leg and foot denoting skin ischemia ( - Fig. 4a,b). The hematologist advised to do the coagulation profile analysis 12 to 15 hours after the last FFP transfusion. To cover the period, we administered $250 \mathrm{mg}$ tranexamic acid intravenously and as soaked gauze dressings over the wound and $50 \mathrm{~mL}$ of cryoprecipitate. Tests revealed a deficiency of factor IX with only $1.2 \%$ of the factor available. A diagnosis of moderate hemophilia B (Christmas disease) was made (less than $1 \%$ : severe, $1-5 \%$ : moderate, $5-50 \%$ :

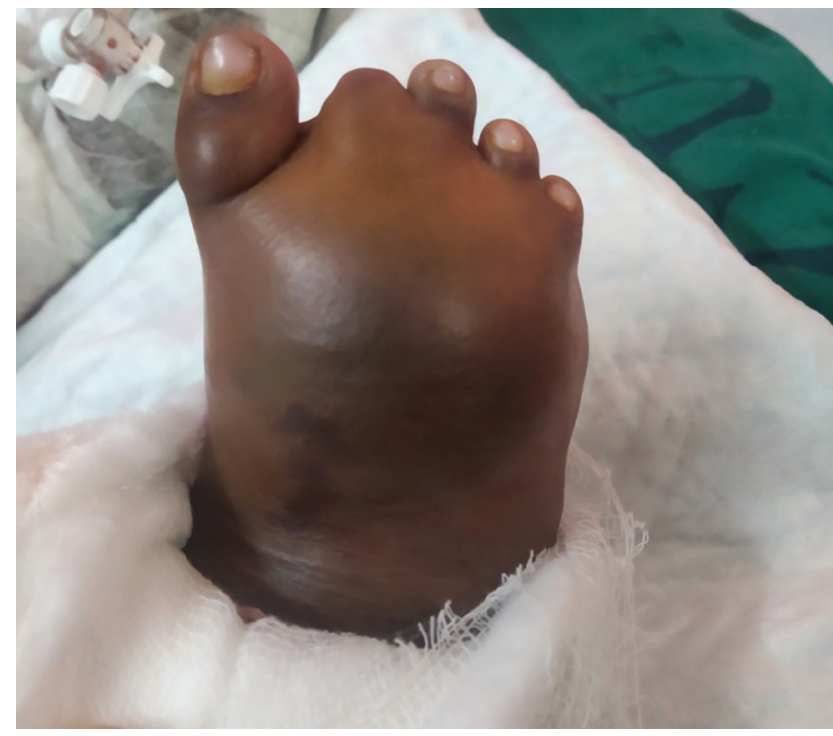

Fig. 3 Subcutaneous spreading of the hematoma causing darkening of the skin.
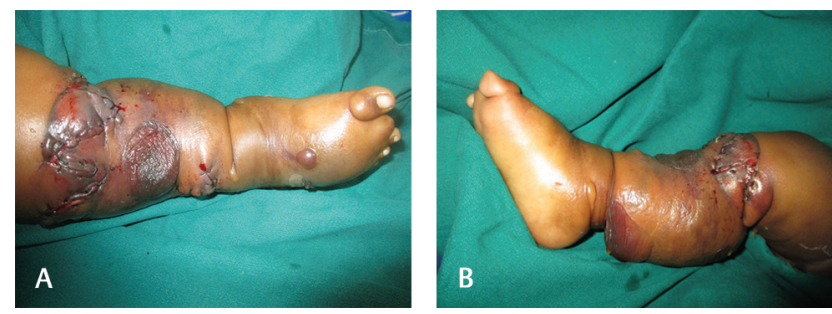

Fig. $4(\mathbf{A}, \mathbf{B})$ Blisters around the leg suggesting compromise in the skin circulation.

mild). ${ }^{1}$ Three hundred IU of factor IX was administered intravenously. The dose was repeated the next day. No further bleeding episodes occurred, and the dressings remained dry. Sutures were removed on the 19th day. Spotty raw areas at the blister sites took 3 weeks to heal. At 3 months follow-up, the child was comfortable, with reduction in the size of the foot and leg ( - Fig. 5a-c). All the other operated sites in the hand and groin healed well.

We have educated the parents about the condition and enrolled the child in the local chapter of the Hemophilic Federation India.

\section{Discussion}

Hemophilia B is a rare X-linked recessive coagulation disorder with an incidence of 1 in 30,000 males. ${ }^{2}$ The diagnosis is often made after a bleeding episode. We do not routinely perform preoperative coagulation profile unless there is a history of bleeding disorder or the patient is on anticoagulation, taking into account the cost/benefit ratio. We could have entertained the possibility of coagulation disorder after the second bleeding episode, when we found diffuse bleeding with no active bleeders.

Incorporating a query about bleeding tendency in the family should become a routine in all pediatric patients preoperatively though the female carriers are usually asymptomatic. 

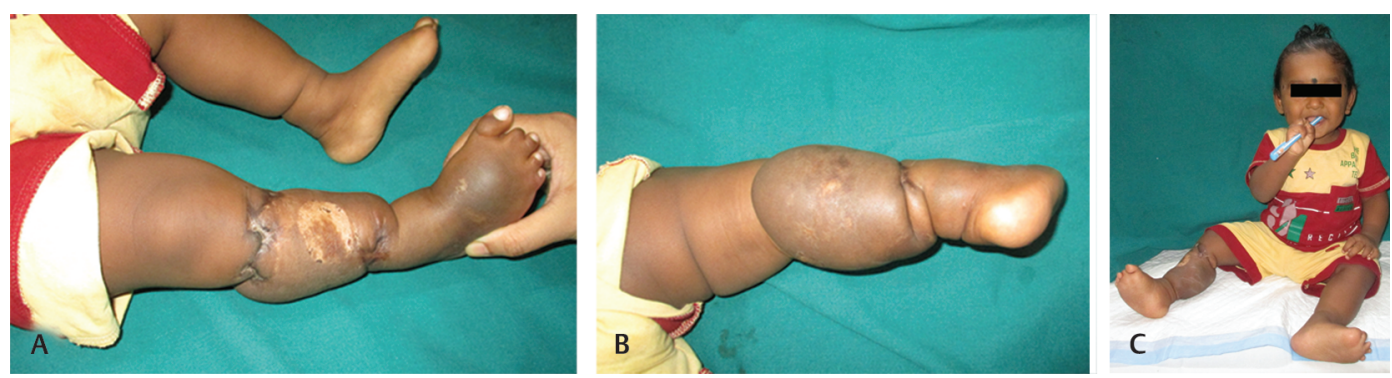

Fig. 5 (A-C) The child at 3 months follow-up with good reduction in the limb size with well healed wounds. The child is cheerful and uses the operated right hand as well.

In children less than 6 months of age, the diagnosis is rare as they do not get hurt and the surgery may be the first insult that brings out the features of hemophilia. A low threshold for suspicion when it occurred and appropriate action could have prevented a near disaster of massive skin necrosis.

Hemophilia, an X-linked recessive disorder, mostly affects males (XY), with the female relatives likely to be carriers. For each male with hemophilia, there are five female carriers. $^{3}$ About 10 to $50 \%$ of hemophilia carriers exhibit bleeding symptoms. ${ }^{4,5}$ The causes are skewed $\mathrm{X}$ chromosome inactivation (lyonization), translocation, or compound heterozygosity for two different mutations. Literature search revealed only two articles where hemophilia was associated with congenital limb differences. ${ }^{6,7}$ In our patient, the association is likely to be incidental.

Coagulation profile testing is usually done after 4 to 5 days after the last dose of FFP, as the half-life of the coagulation factors can go up to 300 hours. ${ }^{8}$ Due to the exigency of the situation, we did the coagulation factor assay 15 hours post FFP transfusion (half-life of factor IX-22 hours). ${ }^{9}$ In the interim period, tranexamic acid in the dose of 10 to $20 \mathrm{mg} / \mathrm{kg}$ body weight three times a day can be given intravenously and also be applied locally. ${ }^{10}$ Tranexamic acid acts as an antifibrinolytic agent by inhibiting plasmin formation and stabilizing the fibrin matrix and clot. It is safe to have 70 to $100 \%$ of factor IX before surgery and not let the levels fall below $30 \%$ till suture removal.

\section{Conclusion}

There have been reports of postoperative bleeding and compartment syndrome in undiagnosed hemophilia patients with the more common type, hemophilia A. ${ }^{11,12}$ Postsurgery compartment syndrome in hemophilia $B$ is even rarer. A high degree of suspicion of coagulation disorder must be entertained when we meet unexpected postoperative bleeding with no major active bleeders.

\section{Disclosure}

The authors have no sources of financial or material funding to disclosure. No portion of this work has been previously presented or published.

\section{Conflict of Interest}

None declared.

\section{References}

1 Niblock A, Donnelly K, Sayers F, Winter P, Benson G. Avoidable compartment syndrome! High index of suspicion for a newly presenting haemophiliac: a case series. Case Rep Emerg Med 2016;2016:3263261

2 Mannucci PM, Tuddenham EG. The hemophilias-from royal genes to gene therapy. N Engl J Med 2001;344(23):1773-1779

3 Lambert C, Meité ND, Sanogo I, et al. Hemophilia carrier's awareness, diagnosis, and management in emerging countries: a cross-sectional study in Côte d'Ivoire (Ivory Coast) Orphanet J Rare Dis 2019;14(1):26

4 Goodeve AC. Hemophilia B: molecular pathogenesis and mutation analysis. J Thromb Haemost 2015;13(7):1184-1195

5 Plug I, Mauser-Bunschoten EP, Bröcker-Vriends AH, et al. Bleeding in carriers of hemophilia. Blood 2006;108(1):52-56

6 Fritz DI, Hanada T, Lu Y, Martin Johnston J, Chishti AH. MPP1/p55 gene deletion in a hemophilia A patient with ectrodactyly and severe developmental defects. Am J Hematol 2019;94(1):E29-E32

7 Hashemieh M, Mansoori B, Tavakoli R, Sheibani K. A case of concurrent proteus syndrome and hemophilia a. Iran J Pediatr 2012;22(2):255-259

8 Anderst JD, Carpenter SL, Abshire TC; Section on Hematology/Oncology and Committee on Child Abuse and Neglect of the American Academy of Pediatrics. Evaluation for bleeding disorders in suspected child abuse. Pediatrics 2013;131(4):e1314-e1322

9 Sindet-Pedersen S, Stenbjerg S. Effect of local antifibrinolytic treatment with tranexamic acid in hemophiliacs undergoing oral surgery. J Oral Maxillofac Surg 1986;44(9):703-707

10 Lancourt JE, Gilbert MS, Posner MA. Management of bleeding and associated complications of hemophilia in the hand and forearm. J Bone Joint Surg Am 1977;59(4):451-460

11 Jones G, Thompson K, Johnson M. Acute compartment syndrome after minor trauma in a patient with undiagnosed mild haemophilia B. Lancet 2013;382(9905):1678

12 Orlian AI, Karmel R. Postoperative bleeding in an undiagnosed hemophilia A patient: report of case. J Am Dent Assoc 1989;118(5):583-584 